\title{
Knowledge of Risk Factors of Health Professionals towards Colorectal Cancer at the Mohammed VI Center of Casablanca for the Treatment of Cancers
}

\author{
Fatima Ezzahra Imad ${ }^{1}$, Houda Drissi' ${ }^{1}$, Nezha Tawfiq ${ }^{2}$, Driss Radallah ${ }^{1}$, Karima Bendahhou ${ }^{3}$ \\ ${ }^{1}$ Biology and Health Laboratory, Research Unit Associated to CNRST-URAC 34, Faculty of Sciences Ben M'Sik, University Hassan \\ II, Casablanca, Morocco \\ ${ }^{2}$ Mohammed VI Center for Cancer Treatment, CHU IbnRochd Casablanca, Morocco Faculty of Medicine and Pharmacy, \\ University Hassan II, Casablanca, Morocco \\ ${ }^{3}$ Cancer Registry of the Greater, Casablanca, Morocco \\ Email: *imadfati91@Gmail.com
}

How to cite this paper: Imad, F.E., Drissi, H., Tawfiq, N., Radallah, D. and Bendahhou, K. (2019) Knowledge of Risk Factors of Health Professionals towards Colorectal Cancer at the Mohammed VI Center of Casablanca for the Treatment of Cancers. Open Access Library Journal, 6: e5577. https://doi.org/10.4236/oalib.1105577

Received: July 4, 2019

Accepted: August 12, 2019

Published: August 15, 2019

Copyright $\odot 2019$ by author(s) and Open Access Library Inc.

This work is licensed under the Creative Commons Attribution International License (CC BY 4.0).

http://creativecommons.org/licenses/by/4.0/

\begin{abstract}
Introduction: Colorectal cancer (CRC) is a major public health problem in Morocco. Knowledge of risk factors is the first step in raising awareness. The objective of this work was to evaluate the knowledge of health professionals working at the Mohammed VI center for the treatment of cancers on risk factors of colorectal cancer. Patients and methods: We conducted a cross-sectional, descriptive, exhaustive study of the hospital personal present $(\mathrm{N}=100)$ stratified according to the activity pole in three groups: G1: Doctors, G2: Nurses and physicists and G3: reception personnel. Results: The participation rate was $(90.91 \%)$. The average age of the health professionals was $31.77 \pm 9.8$. These included doctors $(38 \%)$, nurses (16\%) and support personal (46\%). There was a female predominance. Doctors $(79.5 \%)$ are significantly more aware than nurses (45.9\%) and reception staff $(31.6 \%)$ that age over 40 is a risk factor with $\mathrm{p}=0.0001$. We report a low awareness of nurses and hospital personal compared to physicians about the role of genetic history such as family history of colorectal cancer, familial adenomatous polyposis, and hereditary non-polyposis colorectal cancer, IBD and polyps in preventing $\mathrm{CRC}$ with $\mathrm{p}=0.0001$. Regarding toxic habits, tobacco and alcohol are considered a risk factor for most of medical staff. Obesity is also considered a significant risk factor for $70.5 \%$ of Group 1 and $32.4 \%$ of Group 2 and $36.8 \%$ of Group 3 with $\mathrm{p}=0.001$. The most common preventative factors reported by doctors and health professionals were a diet rich in vegetables and fruits, and regular physical activity. Conclusion: In the light of these results,
\end{abstract}


it appears that the knowledge of the health personal is limited and that it will have to be strengthened by promotion of initial and continuous training on risk factors for colorectal cancer.

\section{Subject Areas}

Epidemiology, Oncology, Public Health

\section{Keywords}

Colorectal Cancer, Knowledge, Risk Factors, Doctors, Nurses, Health Professionals

\section{Introduction}

Colorectal cancer (CRC) is, by its frequency and gravity, a major public health problem in developed countries. In Morocco, it is the third most common cancer with an incidence of 9.6 cases/1,000,000 inhabitants per year for both sexes combined [1].

Nearly one million colorectal cancers are diagnosed, and almost half a million people die each year [2]. This cancer ranks third among the most commonly diagnosed cancers in the world, with a wide geographic variation in incidence and mortality worldwide.

This increasing incidence reflects changes in lifestyle behaviors and their consequences related to Westernization, such as obesity, physical inactivity, high alcohol consumption, high consumption of red meat and smoking. Advancing age, family history, inflammatory bowel disease (IBD), familial adenomatous polyposis (FAP) and Lynch syndrome are also among the risk factors for colorectal cancer [3].

However, the CRC usually develops in a pre-existing lesion. This makes this cancer accessible to a prevention strategy, hence, the need for a good knowledge of its risk factors. Medical personnel are the key actor, beyond their place in the healthcare system and because of the impact of their interactions with patients, they constitute an important lever of information within their social networks and have an important role to play in health promotion and early detection.

The objective of this work was to evaluate the knowledge of colorectal cancer risk factors among health professionals in Mohammed VI center for cancers treatment in Casablanca.

\section{Patients and Methods}

This work was established from a cross-sectional study conducted in the Mohammed VI centre for cancers treatment at CHU IbnRochd in Casablanca. This study took place from March 2017 until August 2017 with hospital staff $(\mathrm{N}=$ 100). Individual interviews were conducted with all medical and paramedical personnel present at the hospital. We filled in the service an anonymous ques- 
tionnaire.

After approval of the local ethics committee and informed consent signed by the health professional after receiving the necessary information for decision-making.

The survey includes a preamble explaining the interest of the study to sensitize the health personnel to answer carefully all questions. The data collected related to socio-professional characteristics, knowledge about the different risk factors (Age over 40 years; Family history; Crohn's disease; toxic habits; physical activity; high fibre foods; too salty foods; vegetables and fruits; red meat; processed and cooked at high temperatures). Then, we stratified the health personnel of the centre by the activity pole, in three groups:

G1: Resident and Internal Doctors, Specialist Doctors, Palliative Care, Epidemiologists.

G2: Nurses, physicists, psychologists, caregivers, radiotherapy technicians.

G3: reception personnel, volunteers, others.

The data entry was carried out by Microsoft Office Excel (2007) and the analysis of the variables by the Epi Info software. The link study by crossing the variables between the different groups was evaluated by the chi-square test. The test is considered significant when $\mathrm{p}<0.05$.

\section{Results}

The Mohammed VI Center for cancers treatment in Casablanca has 110 health professionals, of which 100 (90.91\%) participated in the study by answering the questionnaire. These included doctors (38\%) nurses (16\%) and support personnel (46\%). There was a female predominance; $81 \%$ are women. The average age was $31.77 \pm 9.8$ years old with a minimum age of 19 years and a maximum age of 64 years, with professional seniority of 55 months (Table 1).

Regarding the knowledge of health professionals about colorectal cancer risk factors, $58 \%$ of doctors believed that age older than 40 as a risk factor. The presence of a family history of cancer was considered as risk factors by $75 \%$. More than two-thirds of health professionals thought that IBD, polyps, and PAF are colorectal cancer risk factors while $50 \%$ of survey participants considered Lynch syndrome to be one of the risk factors of colorectal cancer.

Almost half of the health professionals believed that obesity is a risk factor for colorectal cancer, but a small minority (15\%) thought that diabetes can be a risk factor.

Most health professionals considered that diet rich in vegetables (94\%) and fruit and regular physical activity $(85 \%)$ are protective factors while red or processed meat is a risk factor in $85 \%$.

For taking toxic habits (tobacco and alcohol), 77\% indicated that it is a risk factor for colorectal cancer (Table 2).

Regarding the knowledge of health professionals on the risk factors for colorectal cancer according to the activity pole (Table 3 ). 
Table 1. Socioprofessional characteristics of personal.

\begin{tabular}{|c|c|}
\hline Characteristics & Number of cases (\%) \\
\hline \multicolumn{2}{|c|}{ Total sample of participants $(\mathrm{N}=100)$} \\
\hline Mean age(years) & $31.77 \pm 9.8$ \\
\hline \multicolumn{2}{|c|}{ Sex } \\
\hline Men & 19 \\
\hline Women & 81 \\
\hline Professional seniority & 55 mois \\
\hline \multicolumn{2}{|c|}{ Activity pole } \\
\hline Resident doctor & 28 \\
\hline Specialist doctor & 7 \\
\hline Doctor of palliative care & 7 \\
\hline Internal doctor & 2 \\
\hline Nurse & 16 \\
\hline Volunteer & 10 \\
\hline Psychologist & 1 \\
\hline Care assistant & 4 \\
\hline Attached to clinical research & 2 \\
\hline Reception personal & 4 \\
\hline Physicist & 3 \\
\hline Radiotherapy technician & 11 \\
\hline Other & 5 \\
\hline
\end{tabular}

Table 2. Knowledge of risk factors among health professionals.

\begin{tabular}{ccc}
\hline & correct answers \% & False answers \% \\
\hline Age more 40 years & 58 & 42 \\
Family history of cancer & 75 & 25 \\
Crohn's disease or RCH & 67 & 33 \\
Diabete & 15 & 85 \\
Lynch syndrome & 50 & 50 \\
Polyp at the colon & 66 & 34 \\
FAP & 62 & 38 \\
Tabacco & 78 & 22 \\
Alcohol & 77 & 23 \\
Red meat & 85 & 15 \\
Processed meats & 77 & 23 \\
Meat cooked at high temperature & 32 & 68 \\
Diet low in fiber & 66 & 34 \\
Too salty food & 26 & 74 \\
Obesity & 50 & 50 \\
Regular physical activity & 85 & 15 \\
Diets high in vegetables and fruits & 94 & 6 \\
\hline
\end{tabular}


Table 3. State of knowledge of risk factors among health professionals according to the activity pole.

\begin{tabular}{|c|c|c|c|}
\hline \multirow{2}{*}{ Qualification } & Group 1 & Group 2 & Group 3 \\
\hline & Correct answers \% & Correct answers \% & Correct answers \% \\
\hline Age more 40 years & 79.5 & 45.9 & 31.6 \\
\hline Family history of cancer & 86.4 & 70.3 & 57.9 \\
\hline Crohn's disease or $\mathrm{RCH}$ & 84.1 & 59.5 & 42.1 \\
\hline Diabete & 15.9 & 16.21 & 10.5 \\
\hline Lynch syndrome & 79.5 & 29.7 & 21.1 \\
\hline Polyp at the colon & 86.4 & 59.5 & 31.6 \\
\hline FAP & 86.4 & 48.6 & 31.6 \\
\hline Tabacco & 79.5 & 70.3 & 89.5 \\
\hline Alcohol & 72.7 & 75.7 & 89.5 \\
\hline Red meat & 86.4 & 83.8 & 84.2 \\
\hline Processed meats & 84.1 & 75.7 & 63.2 \\
\hline Meat cooked at high temperature & 25 & 37.8 & 36.8 \\
\hline Diet low in fiber & 81.8 & 56.8 & 47.4 \\
\hline Too salty food & 27.3 & 29.7 & 15.8 \\
\hline Obesity & 70.5 & 32.4 & 36.8 \\
\hline Regular physical activity & 77.3 & 91.9 & 89.5 \\
\hline Diets high in vegetables and fruits & 93.2 & 97.3 & 89.5 \\
\hline
\end{tabular}

Group $1(79.5 \%)$ are significantly more aware than group 2 (45.9\%) and group $3(31.6 \%)$ than age over 40 is a risk factor with $\mathrm{p}=0.0001$.

The presence of family history of colorectal cancer is considered a risk factor by $86.4 \%$ of group 1 vs $70.3 \%$ of group 2 and $57.9 \%$ of group 3 .

As for the presence of polyps and Lynch syndrome and FAP were considered risk factors for most doctors $(86.4 \%, 79.5 \%$ and $86.4 \%)$ respectively, compared with the nurse $(59.5 \%, 29.7$, and $48.6 \%)$ and $(31.6 \%, 21.1$ and 31.6$)$ of the reception personal respectively.

Regarding toxic habits; smoking and alcoholism are considered risk factors in group $1(79.5 \%, 72.7 \%)$ respectively; $(70.3 \%, 75.7 \%)$ of group 2 and $(89.5 \%$, $89.5 \%)$ of group 3.

The red meat was a risk factor for the majority of staff of the 3 groups, but a small minority (4.3\%) thought that it plays no role.

Meat cooked at high temperature is a risk factor; $25 \%$ of G1; $37.8 \%$ of G2 vs. $36.8 \%$ of G3 indicated it is a risk factor for colorectal cancer.

Obesity is also considered an important risk factor for $70.5 \%$ of group 1 , $32.4 \%$ of group 2 and $36.8 \%$ of group 3 . 
The analysis showed that $77.3 \%$ of group $1,91.9 \%$ of group 2 and $89.5 \%$ of group 3 indicate that regular physical activity is a protective factor.

The diet rich in vegetables and fruits is considered a risk factor by most health professionals in the 3 groups (Table 3 ).

Tables 4-6 show the fair responses of participants in the 3 status groups to questions on risk factors for colorectal cancer.

Specialist doctors had excellent knowledge of risk factors followed by resident doctors and palliative care doctors, in contrast, nurses are generally better informed about colorectal cancer risk factors as the reception personnel.

The main source of information for health professionals on risk factors for colorectal cancer was initial medical education (38\% in G1 vs. $18 \%$ of G2 and $5 \%$ of G3, p = 0.001), followed by scientific articles (30\% \% in G1, 16\% in G2 and $7 \%$ of G3).

The other sources of information were TV, radio reported by $4 \%$ in G1, 6\% of G2 and $10 \%$ of G3 with $\mathrm{p}=0.001$ for TV, and $1 \%$ in G2, $2 \%$ in G2 vs. $3 \%$ in G3 with $\mathrm{p}=0.001$ for radio (Table 7).

Table 4. State of knowledge of risk factors in group 2 according to the status doctors.

\begin{tabular}{|c|c|c|c|c|}
\hline & $\begin{array}{c}\text { Doctors of } \\
\text { palliative care } \\
(\%)\end{array}$ & $\begin{array}{l}\text { Internal } \\
\text { doctors } \\
(\%)\end{array}$ & $\begin{array}{c}\text { Resident } \\
\text { Doctors } \\
(\%)\end{array}$ & $\begin{array}{c}\text { Specialist } \\
\text { doctors } \\
(\%)\end{array}$ \\
\hline Age more 40 years & 42.9 & 50 & 89.3 & 100 \\
\hline Family history of cancer & 100 & 50 & 85.7 & 83.3 \\
\hline Crohn's disease or RCH & 100 & 0 & 89.3 & 66.7 \\
\hline Diabete & 14.3 & 0 & 17.9 & 16.7 \\
\hline Lynch syndrome & 28.6 & 50 & 96.4 & 83.3 \\
\hline Polyp at the colon & 85.7 & 0 & 92.9 & 83.3 \\
\hline FAP & 57.1 & 50 & 96.4 & 83.3 \\
\hline Tabacco & 100 & 83.3 & 71.4 & 100 \\
\hline Alcohol & 100 & 66.7 & 64.3 & 100 \\
\hline Red meat & 57.1 & 83.3 & 92.9 & 100 \\
\hline Processed meats & 83.3 & 50 & 85.7 & 85.7 \\
\hline $\begin{array}{l}\text { Meat cooked at } \\
\text { high temperature }\end{array}$ & 14.3 & 50 & 21.4 & 50 \\
\hline Diet low in fiber & 50 & 50 & 85.7 & 100 \\
\hline Too salty food & 42.9 & 0 & 21.4 & 33.3 \\
\hline Obesity & 66.7 & 0 & 71.4 & 85.7 \\
\hline Regular physical activity & 83.3 & 50.0 & 71.4 & 100 \\
\hline $\begin{array}{c}\text { Diets high in } \\
\text { vegetables and fruits }\end{array}$ & 83.3 & 50.0 & 96.4 & 100 \\
\hline
\end{tabular}


Table 5. State of knowledge of risk factors in group 2 according to the status.

\begin{tabular}{cccccc}
\hline & $\begin{array}{c}\text { Care } \\
\text { assistant }(\%)\end{array}$ & $\begin{array}{c}\text { Nurse } \\
(\%)\end{array}$ & $\begin{array}{c}\text { Physicist } \\
(\%)\end{array}$ & $\begin{array}{c}\text { Psychologist } \\
(\%)\end{array}$ & $\begin{array}{c}\text { Radiotherapy } \\
\text { technician }(\%)\end{array}$ \\
\hline Age more 40 years & 0 & 62.5 & 33.3 & 0 & 36.4 \\
Family history of cancer & 0 & 81.2 & 66.7 & 100 & 72.7 \\
Crohn's disease or RCH & 50 & 62.5 & 66.7 & 100 & 45.5 \\
Diabete & 0 & 25 & 0 & 0 & 0 \\
Lynch syndrome & 0 & 50 & 0 & 0 & 9.1 \\
Polyp at the colon & 25 & 68.8 & 33.3 & 100 & 54.5 \\
FAP & 25 & 75 & 0 & 0 & 27.3 \\
Tabacco & 50 & 68.8 & 66.7 & 100 & 72.7 \\
Alcohol & 50 & 81.2 & 66.7 & 100 & 72.7 \\
Red meat & 50 & 100 & 66.7 & 100 & 72.7 \\
Processed meats & 50 & 87.5 & 100 & 100 & 54.5 \\
Meat cooked at & 25 & 50 & 33.3 & 100 & 9.1 \\
high temperature & & & & & 51.5 \\
Diet low in fiber & 50 & 50 & 66.7 & 100 & 54.5 \\
Too salty food & 0 & 31.2 & 66.7 & 0 & 18.2 \\
$\quad$ Obesity & 0 & 50 & 0 & 100 & 9.1 \\
$\begin{array}{c}\text { Regular physical activity } \\
\text { Diets high in }\end{array}$ & 70 & 93.8 & 100 & 100 & 81.8 \\
vegetables and fruits & 80 & 93.8 & 100 & 100 & 100 \\
\hline
\end{tabular}

Table 6. State of knowledge of risk factors in group 3 according to the status.

\begin{tabular}{ccc}
\hline & Volunteer (\%) & Reception personal (\%) \\
\hline Age more 40 years & 30 & 25 \\
Family history of cancer & 30 & 80 \\
Crohn's disease or RCH & 20 & 50 \\
Diabete & 0 & 0 \\
Lynch syndrome & 10 & 0 \\
Polyp at the colon & 10 & 50 \\
FAP & 10 & 50 \\
Tabacco & 90 & 100 \\
Alcohol & 90 & 100 \\
Red meat & 80 & 75 \\
Processed meats & 50 & 75 \\
Meat cooked at high temperature & 30 & 50 \\
Diet low in fiber & 20 & 75 \\
Too salty food & 0 & 0 \\
Obesity & 30 & 25 \\
Regular physical activity & 90 & 75 \\
Diets high in vegetables and fruits & 80 & 80 \\
\hline
\end{tabular}


Table 7. Source of information of health professionals.

\begin{tabular}{ccccc}
\hline Source of information & Group 1 (\%) & Group 2 (\%) & Group 3 (\%) & P value \\
\hline Academic curriculum & 38 & 18 & 5 & 0.001 \\
Reading scientific articles & 30 & 16 & 7 & 0.02 \\
Television & 4 & 6 & 10 & 0.001 \\
Internet & 21 & 22 & 9 & 0.5 \\
Discussion with friends & 16 & 12 & 10 & 0.3 \\
Radio & 1 & 2 & 3 & 0.1 \\
Other & 3 & 3 & 3 & 0.5 \\
\hline
\end{tabular}

\section{Discussion}

This study was conducted to assess the knowledge of health professionals, working at the center of cancer of Casablanca, on the risk of risk factors for colorectal cancer.

Despite a growing promotion of this type of cancer in the medical press and the media, more than one in two people are dissatisfied with the information received. Confronted with a growing demand for information from patients about environmental health risks, doctors in turn deplore the lack of reliable and easily accessible information on this topic.

Lack of knowledge about risk factors for CRC could have an impact on the incidence of colorectal cancer in the long term. An earlier study from Malaysia reported that only $4.1 \%$ had a good knowledge of CRC and its screening [4].

However, other Hong Kong studies [5] data from Australia [6] [7] and United States [8] also reported low levels of knowledge of the CCR.

Participation rates $(90.91 \%)$ are high, compared to Western studies; the doctors were the only professional group that had a satisfactory knowledge of risk factors while nurses and reception personnel need ongoing training and awareness.

The age of over 40 years was cited as a risk factor by $79.5 \%$ of doctors $v s$ $45.9 \%$ of nurses and $31.6 \%$ of reception personnel, our results support a study in Asia, which found that about $43 \%$ of health personnel were aware that age over 40 is a risk factor for colorectal cancer. $57.9 \%$ of participants, being misinformed was the barrier to screening [9].

Our study reports low awareness among nurses and hospital staff compared to physicians about the role of family history, such as Lynch syndrome, FAP, IBD and polyps in preventing CRC. This result is similar to other studies that found that very few health professionals were aware of the risk factors; only $25.9 \%$ could identify the genetic background as risk factors for CRC [10].

The most common factors reported by physicians and health professionals were red meat, a diet rich in vegetables and fruits, and regular physical activity.

In addition, our results disagree with previous results a study conducted in the United States where the reception personnel was less aware of the role of physi- 
cal activity in the prevention of colorectal cancer [11].

It is important to note here that health professionals should seize this opportunity, play an active role in communicating messages for cancer prevention through lifestyle modification [12].

Appropriate continuing education programs and other interventions are needed to improve the knowledge of health professionals.

\section{Conclusion}

The results of this study showed that health professionals' knowledge of risk factors for colorectal cancer was not satisfactory enough, which could be a cause of the increased incidence of colorectal cancer cases diagnosed at advanced stages. It is necessary to introduce colorectal cancer education in nursing schools, especially in the public sector. Continuing education in the workplace can be advantageous. It is necessary to promote the medical training of health personnel who are in the front line of contact with patients, in the field of risk factors in order to raise awareness and improve prevention against this cancer.

\section{Conflicts of Interest}

The authors declare no conflicts of interest regarding the publication of this paper.

\section{References}

[1] RCRC (2016) Registre des Cancers de la Région de grand Casablanca, données 2008-2012.

[2] Mallem, D. (2010) Les cancers colorectaux dans les wilayas de Batna. Etude épidémiologique clinique et thérapeutique. Thèse doctorat en sciences médicales, Université de Batna, EL Hadj Lakhdar, Faculté de médecine, Algérie, 239.

[3] Burke, K.M., Mohn-Brown, E.L. and Eby, L. (2011) Medical Surgical Nursing Care. 3rd Edition, Pearson, Upper Saddle River, 674-691.

[4] Harmy, M.Y., Norwati, D., Noor, N.M. and Amry, A.R. (2011) Knowledge and Attitude of CRC Screening among Moderate Risk Patients in West Malaysia. Asian Pacific Journal of Cancer Prevention, 12, 1957-1960.

[5] Tam, T.K.W., Ng, K.K. and Lau, C.M. (2011) Fecal Occult Blood Screening: Knowledge, Attitudes, and Practice in Four Hong Kong Primary Care Clinics. Hong Kong Medical Journal, 17, 350-357.

[6] Christou, A. and Thompson, S.C. (2012) CRC Screening Knowledge, Attitudes and Behavioural Intention among Indigenous Western Australians. BMC Public Health, 12, 528. https://doi.org/10.1186/1471-2458-12-528

[7] Javanparast, S., Ward, P.R., Carter, S.M. and Wilson, C.J. (2012) Barriers to and Facilitators of CRC Screening in Different Population Subgroups in Adelaide, South Australia. Medical Journal of Australia, 196, 521-523. https://doi.org/10.5694/mja11.10701

[8] Sanderson, P.R., Weinstein, N., Teufel-Shone, N. and Martinez, M.E. (2011) Assessing CRC Screening Knowledge at Tribal Fairs. Preventing Chronic Disease, 8, 16.

[9] Thanapirom, K., Treeprasertsuk, S. and Rerknimitr, R. (2012) Awareness of Colo- 
rectal Cancer Screening in Primary Care Physicians. Journal of the Medical Association of Thailand, 95, 859-865.

[10] Omran, S., Barakat, H., Muliira, J.K. and Aljadaa, N. (2015) Knowledge, Experiences, and Barriers to Colorectal Cancer Screening: A Survey of Health Care Providers Working in Primary Care Settings. Journal of Cancer Education, 30, 53-61. https://doi.org/10.1007/s13187-014-0676-0

[11] Coups, E.J., Hay, J. and Ford, J.S. (2008) Awareness of the Role of Physical Activity in Colon Cancer Prevention. Patient Education and Counseling, 72, 246-251. https://doi.org/10.1016/j.pec.2008.03.007

[12] Stead, M., Caswell, S. and Craigie, A.M. (2012) Understanding the Potential and Challenges of Adenoma Treatment as a Prevention Opportunity: Insights from the BeWEL Formative Study. Preventive Medicine, 54, 97-103.

https://doi.org/10.1016/j.ypmed.2011.10.017 